\title{
Some epidemiological problems of iron deficiency anaemia
}

\author{
By P. C. Elwood, Medical Research Council, Epidemiological Research Unit, Cardiff
}

One of the fundamental aspects of any disease or deficiency state which is of interest to an epidemiologist, and the aspect which is of greatest interest to this symposium, is the importance of that condition in the population as a whole. Assessments of importance depend on both the prevalence in the community and the amount of morbidity or mortality caused by the condition.

\section{Importance}

Iron deficiency anaemia, as conventionally defined in clinical practice, for example the criteria in WHO (1959), has been shown to be common in this country in women of all ages (Kilpatrick, 1961 ), and in the elderly of both sexes (Kilpatrick \& Hardisty, I96r; Parsons, Withey \& Kilpatrick, I965). However the evidence presented in these and many other similar studies is based simply on the proportion of persons found to have levels of circulating haemoglobin below 'the lower limit of the normal range' and this point in the distribution of haemoglobin levels is usually chosen in an arbitrary manner. The use of such a concept has been shown to be misleading (Murphy \& Abbey, 1967), and indeed any single diagnostic criterion of anaemia in terms of a level of circulating haemoglobin concentration is unreasonable unless it is shown that levels below this are significantly often correlated with ill-health. Furthermore the definition of a single level of circulating haemoglobin within each sex as a criterion of iron deficiency is unreasonable in view of the significant associations of haemoglobin level with other variates such as age, body-weight and phase within the menstrual cycle. Again, the evidence presented by epidemiologists of a negatively skewed distribution of haemoglobin levels in women (Elwood, 1964 ; Elwood, Waters, Greene \& Wood, 1967), though not in adolescents (Elwood, Withey \& Kilpatrick, I964) and probably not in males, is of importance only if it is shown that low levels significantly often indicate disease or ill-health.

In an attempt to assess the importance of low haemoglobin levels in a population, we recently conducted a large community screening survey in which we saw just over I000 women (Table I). Forty-four women were found to have haemoglobin levels below $10.0 \mathrm{~g} / 100 \mathrm{ml}$ blood and, of these, thirty-seven who were not already being treated by their general practitioners agreed to be referred to a hospital outpatient department for further examination and investigation by consultant physicians. In eight cases further action of probable relevance to the iron deficiency was advised. One woman had injections for haemorrhoids, one who could not tolerate oral iron was admitted for blood transfusion, and six were advised to have uterine dilation and curettage. One hundred and twenty women were found to have haemoglobin levels below $12 \circ \mathrm{g}$, and these were asked to supply three specimens of faeces for testing for occult blood. To enable the results of these tests to be evaluated a representative sample of a similar number of women with haemoglobin levels above $12.0 \mathrm{~g}$ 
were also screened in the same way. Of the women with low haemoglobin levels, I $6 \%$ gave at least one positive test. This is higher, but not significantly so, than the proportions in women who had haemoglobin levels above $12.0 \mathrm{~g}(8 \%)$. However, in the women with haemoglobin levels below $12.0 \mathrm{~g}$ there was no evidence of a significant association between the proportion of positive results and haemoglobin level, and on re-testing, only four of the fifteen women who had given a positive result on the first occasion did so again. These results give little support to the not uncommonly expressed belief that anaemia is commonly a sign of a serious underlying pathological condition, and that this is 'all too frequently' (Harris, 1963) a malignant tumour of the gastro-intestinal tract.

Table I. Distributions of haemoglobin level and packed cell volume among women in a recent population survey

\begin{tabular}{|c|c|c|c|}
\hline \multicolumn{2}{|c|}{ Haemoglobin level } & \multicolumn{2}{|c|}{ Packed cell volume } \\
\hline & $\begin{array}{l}\text { No. of } \\
\text { subjects }\end{array}$ & $\%$ & $\begin{array}{l}\text { No. of } \\
\text { subjects }\end{array}$ \\
\hline $6 \cdot 5$ & $\mathbf{I}$ & $<30$ & 14 \\
\hline $7 \cdot 0$ & 3 & 30 & 5 \\
\hline $7 \cdot 5$ & 4 & $3 I$ & 3 \\
\hline 8.0 & 8 & 32 & 8 \\
\hline $8 \cdot 5$ & 4 & 33 & 17 \\
\hline $9 \cdot 0$ & 6 & 34 & 20 \\
\hline $9-5$ & I 8 & 35 & 26 \\
\hline 10.0 & I I & 36 & 25 \\
\hline 10.5 & 20 & 37 & 45 \\
\hline I I.O & 18 & $3^{8}$ & 90 \\
\hline I I 5 & 27 & 39 & 122 \\
\hline $12 \cdot 0$ & 59 & 40 & 152 \\
\hline $2 \cdot 5$ & 79 & $4 I$ & 129 \\
\hline $13 \cdot 0$ & $16_{5}$ & 42 & 145 \\
\hline $13 \cdot 5$ & 230 & 43 & 112 \\
\hline $14 \cdot 0$ & I 78 & 44 & 60 \\
\hline I $4 \cdot 5$ & 142 & 45 & 42 \\
\hline 15.0 & 52 & 46 & 15 \\
\hline I $5.5+$ & 55 & $\begin{array}{l}47 \\
48+\end{array}$ & $\begin{array}{l}15 \\
16\end{array}$ \\
\hline Total & 1080 & Total & I06I* \\
\hline
\end{tabular}

In order to assess further the importance of low haemoglobin levels in terms of morbidity, we conducted two large-scale community studies of the symptomatology of iron deficiency anaemia. In neither study was any evidence found of a significant association between haemoglobin level and the severity of a variety of symptoms. One of these studies is reported by Wood \& Elwood (I966); results for the other are summarized in Table 2 . Both these cross-sectional studies were followed by randomized controlled trials of the effects of oral iron therapy on symptoms, and again in neither was there any convincing evidence of a beneficial effect of iron. The first of these studies, to which only women with haemoglobin levels above 10.0 $\mathrm{g}$ were admitted, was reported in Elwood \& Wood (1966). Results from the other trial, to which women with haemoglobin levels between 8.0 and $12.0 \mathrm{~g}$ were admitted, 
are summarized in Table 3 . It is apparent from Table 3 that, although several significant changes in symptoms occurred during this trial, for no symptom did the effect of iron differ significantly from that of the placebo. Furthermore, although the consistency of the sign of the changes in the group given iron is technically significant (the probability of getting six negatives out of six on chance grounds alone is about 0.02 ), for only five out of the six symptoms is the sign of the difference between the two groups negative and the probability of obtaining such a result by chance alone is not significant (approximately 0.09 ).

Table 2. Correlation coefficients ( $\mathrm{r}$ ) of symptoms (graded on arbitrary seven-point scales) and haemoglobin level in 880 female subjects seen in a community-based study

\begin{tabular}{lc}
\multicolumn{1}{c}{ Symptom } & $r$ \\
Irritability & 0.01 \\
Palpitations & $0.16 *$ \\
Dizziness & -0.05 \\
Breathlessness & -0.02 \\
Fatigue & 0.03 \\
Headache & -0.01
\end{tabular}

If a symptom increases in severity with a fall in haemoglobin level, its sign will be negative.

* Significant at $P<0.05$.

Table 3. Mean values with their standard errors for changes in symptoms (graded on arbitrary seven-point scales) and haemoglobin level in ninety women with levels between 8.0 and $12.0 \mathrm{~g} / 100 \mathrm{ml}$, given either iron by mouth or a placebo tablet for 8 weeks in a randomized clinical trial

\begin{tabular}{lccc}
\multicolumn{1}{c}{ Symptom } & \multicolumn{2}{c}{ Therapy } & Difference \\
\multicolumn{1}{c}{ Iron $(a)$} & Placebo $(b)$ & $(a-b)$ \\
Irritability & $-0.03 \pm 0.37$ & $-0.78 \pm 0.30$ & $0.76 \pm 0.48$ \\
Palpitations & $-0.37 \pm 0.34$ & $0.03 \pm 0.35$ & $-0.40 \pm 0.49$ \\
Dizziness & $-0.79^{*} \pm 0.25$ & $-0.65 \pm 0.34$ & $-0.14 \pm 0.42$ \\
Brcathlessness & $-0.1 \mathrm{I} \pm 0.18$ & $0.19 \pm 0.20$ & $-0.29 \pm 0.27$ \\
Fatigue & $-0.13 \pm 0.27$ & $0.30 \pm 0.22$ & $-0.43 \pm 0.34$ \\
Headache & $-\mathbf{I} \cdot 05^{*} \pm 0.37$ & $-0.97^{*} \pm 0.38$ & $-0.08 \pm 0.53$ \\
Hacmoglobin level & $\mathrm{I} \cdot 5^{*} \pm 0.21$ & $-0.003 \pm 0.12$ & $\mathrm{I} \cdot 58^{*} \pm 0.24$ \\
No. of subjects & 49 & $4 \mathrm{I}$ & 90
\end{tabular}

A negative sign indicates an improvement in a symptom.

* Significant at $P<0.05$.

All these studies give little evidence that the clinical concept of iron deficiency anaemia as an important condition, either per se or as a manifestation of a serious underlying pathological condition, is applicable to the community as a whole. Although we do not regard these studies as conclusive they do suggest that degrees of iron deficiency which really matter are very much less frequent in the community than is suggested by simple studies of the prevalence of 'anaemia'. 
The concept of iron deficiency has recently been extended considerably by studies of Beutler, Larsh \& Gurny (1960) and others, which led to the concept of 'sideropenia', or 'iron deficiency without anaemia'. In a randomized controlled trial Beutler et al. (1960) gave, in random order, iron and placebo tablets to women who complained of 'chronic fatigue' and who had 'normal' haemoglobin levels. They assessed the change in the symptoms of these women in a conventional clinical interview, and they reported a beneficial effect of iron. We recently conducted a similar study in a community sample of women selected by criteria similar to those of Beutler $e t$ al. (1960), but, as it seemed to us almost impossible to conduct a clinical interview at the end of such a trial in a truly 'blind' manner, we assessed the change in symptoms by a rather sophisticated self-administered questionnaire, developed from the one described by Wood \& Elwood (1966). We failed to detect any beneficial effect of iron on symptoms and we therefore feel that further evidence is required to establish a beneficial effect on the administration of iron to such subjects, or to justify an increase in the intake of iron in the community as a whole simply because 'fatigue' is a common symptom.

We feel, however, that an epidemiological approach to the interpretation of haemoglobin level as an index of 'health' should consider all levels of its distribution and not simply low levels. This seems advisable in view of the evidence, much of which is post hoc ergo propter hoc, that a high blood haemoglobin or haematocrit is not necessarily beneficial (Dawber \& Kannel, 196r; Burch \& De Pasquale, 1962; Birnbaum, 1963 ; Eisenberg, 1966$)$.

\section{Aetiology}

The level of circulating haemoglobin is largely dependent on the body content of iron, which is ultimately dependent on the absorption and the loss of iron from the body. Neither the total absorption, nor the total loss of iron can be easily measured in an individual, and much less in a community sample. Indirect estimates of absorption can, however, be based on information relating to dietary intake, and assumptions relating to total losses in women can reasonably be based on measurements of menstrual losses of iron as the other sources of loss are probably small and constant, relative to menstrual loss.

We will shortly report a study of randomly selected population samples, stratified by haemoglobin level, in which the dietary intakes and the menstrual losses of iron were measured, and the associations between these variates and the level of circulating haemoglobin were assessed. The results of these studies suggest that, in the determination of the level of circulating haemoglobin, the total dietary intake of iron, independent of body-weight, plays a relatively small part, whereas the menstrual loss of iron is a factor of some importance. However, the interpretation of results from studies such as these is difficult, as statistical estimates of dependence reflect not only the true strength of the associations but also the errors in the estimation of the variates themselves. Our results, therefore, could be explained in part by the 27 (I) 2 
fact that the errors in estimates of dietary intake of iron are probably considerably greater than errors in estimates of menstrual loss of iron.

However, whatever the aetiological factors, iron deficiency represents an imbalance between intake and loss of iron, and it should be possible to correct this in almost every instance, by a sufficient increase in the dietary intake of available iron. The effects of dietary supplements of iron on haemoglobin level are therefore of interest, and several studies have been reported in which small amounts of iron have been given to groups of subjects over fairly long periods. In some of these studies iron has been added to bread and given to children (Mackay, Dobbs \& Bingham, 1945; Widdowson \& McCance, 1954) or adults (Harrill, Hoene \& Johnston, 1957; Elwood, I963). In others, small amounts of iron have been given in tablet form to children or adults (Garry, Sloan, Weir \& Wishart, 1954; Antila, 1962; Natvig, Bjerkedal \& Jonassen, I963; Scott \& Heller, I964) or to pregnant women (De Leeuw, Lowenstein \& Yang-Shu, I966; Paintin, Thompson \& Hytten, I966). These and other studies are reviewed elsewhere (Elwood, I965a, 1966). However the results of these studies conflict and give no clear and consistent evidence of a beneficial effect of small iron supplements on haemoglobin level. Unfortunately there are certain aspects of these studies which can easily be criticized, notably that, in most of them other than in the two based on pregnant women, few, if any, of the subjects are likely to have been iron-deficient. Furthermore the results of all such studies are difficult to interpret since iron supplements, particularly if large, may have a haematinic effect in subjects who are not iron-deficient. The evidence is controversial but is reviewed by Paintin et al. (1966) and De Leeuw et al. (1966). A rise in haemoglobin level consequent on the administration of iron cannot therefore be accepted as unequivocal proof of iron deficiency. While a dilemma in this context is unlikely to arise in clinical work, and is unimportant if it does, in studies such as those referred to above, in which relatively small doses of added iron are given to subjects who are not grossly iron-deficient, the interpretation of small changes in mean haemoglobin levels may be exceedingly difficult.

In an attempt to resolve some of the difficulties and to get some idea as to the size of the supplement of iron which will protect a community from iron deficiency, we are at present conducting two studies in which small daily supplements of iron are being given to groups of female subjects. We have chosen subjects for our studies who should be sensitive to small changes in iron balance, namely, a representative sample of adolescent girls, many of whom, owing to rapid growth, are likely to be negative in iron balance, and a population sample of adult women who had recently been found to have low haemoglobin levels and can be presumed still to be in negative iron balance. Preliminary results will be presented here from only one of these studies and this will be described more fully later (W. J. Greene \& P. C. Elwood, unpublished).

Following a community screening survey in which over 1000 women were seen (see Table I) all the women with haemoglobin levels below $12.0 \mathrm{~g}$ were given sufficient iron therapy to raise their haemoglobin levels above $12.0 \mathrm{~g}$. Each was then put on a small daily dose of iron, of, at random, o, ro or $30 \mathrm{mg}$. After 6 months, the mean 
level of the group which received no iron supplement showed a change of $-\mathrm{r} \cdot \mathrm{O} \mathrm{I} \pm$ $0.18 \mathrm{~g}$. This fall is significant at $P<0.05$ and is significantly greater than the changes in the two groups which received Io and $30 \mathrm{mg}$ iron/day, though these were themselves homogeneous, $+0.01 \pm 0.24$ and $-0.24 \pm 0.22$ respectively. This study is not completed, but it does confirm that conventional iron therapy has little lasting effect in many women. It also suggests that a community may be adequately protected from iron deficiency by a relatively small daily supplement of iron. While we have not yet explored the effects of daily supplements of less than ro mg iron, the results of this trial, as they relate to almost all the women likely to be in negative iron balance in the original population screened, suggest that smaller supplements of a readily available iron preparation may well lead to an appreciable reduction in the proportion of the community with low haemoglobin levels.

\section{Prevention}

Other than in a few selected groups, such as pregnant women, and even in these, prevention of iron deficiency by the distribution of iron tablets is costly, inefficient and not without dangers (D'Arcy \& Howard, 1962). If iron deficiency is to be prevented at a national level, then this can probably be most easily achieved by the addition of an easily absorbed form of iron to a commonly consumed foodstuff. In this country such a policy has been in operation for a considerable number of years, as, since the Flour Order (Great Britain: Parliament, I953), iron has been added to all white flour to restore its iron content to that of a high extraction flour $(1.65 \mathrm{mg}$ iron/roo g flour).

The average daily intake of iron in this country is estimated to be about $14.3 \mathrm{mg}$ per person, and of this about $\mathrm{I} \cdot 8$ to $2.6 \mathrm{mg}(\mathrm{r} 2-\mathrm{I} 8 \%)$ is estimated to come from white bread, and a further $1 \cdot 4 \mathrm{mg}(10 \%)$ from flour, or products of flour (Ministry of Agriculture, Fisheries and Food: National Food Survey Committee, 1963). At the present level of extraction of white flour (about $72 \%$ ) and the present level of fortification of this flour with iron, only about one-third of the iron content of white flour is added during milling. That is, each person receives on average about $\mathrm{I}^{\prime} 3 \mathrm{mg}$ of iron each day, or $10 \%$ of their total daily intake of iron, because of the provisions of the flour orders.

These figures represent average consumption, and are based on household expenditure on food. The more detailed analyses presented in the same report suggest that, while the annual consumption of white bread is showing a gradual downward trend, households in certain sections of the community, such as families with four or more children, families with low incomes, families with several children and a pregnant mother, devote a greater than average proportion of their total food expenditure on white bread. Although there does not seem to be a 'social class gradient' in the distribution of haemoglobin level in the community in this country (Elwood, $1965^{b}$ ) nor, in a recent study in South Wales, did there appear to be a significant correlation in women between the amount of bread consumed and haemoglobin level (the partial correlation coefficient between the weight of bread consumed and the level of 
circulating haemoglobin, body-weight held constant, was $-0 \cdot 102 \pm 0 \cdot 26$ ), yet it is not unreasonable to assume that some, if not all the above sections of the community represent groups with a greater than average risk of becoming iron-deficient. The importance of bread, therefore, as a source of dietary iron may in fact be greater than suggested by the average figures for consumption quoted above. This would also be true if the availability of the iron added to the flour were higher than that of iron obtained from other dietary sources.

We have just completed a series of studies of the availability to human subjects of several preparations of iron added to flour used to bake bread. These studies will be described in detail elsewhere (in preparation) and only a summary of some of the results is presented here. A double radioactive isotope method was used (Eakins \& Brown, 1965 ), and each subject was given ferrous sulphate baked into bread, together with another iron preparation, baked into a different portion of bread. Bread was given as part of a breakfast, which, for some of the subjects, included a freshly boiled egg. The iron preparations studied, in addition to ferrous sulphate, were reduced iron $\mathrm{BP}$ and ferric ammonium citrate $\mathrm{BP}$, both as defined in the flour order (Great Britain: Parliament, 1963), and a form of powdered iron obtained from a source which supplies iron to the flour-milling industry. This latter is, we believe, one of the main forms of iron used for addition to flour in this and other countries. Over seventy subjects co-operated in these studies and the majority of these were haematologically 'normal' but a small proportion were iron-deficient (sixteen had haemoglobin levels below I2.0 g), and a few (ten) had gastric achlorhydria.

Table 4 and Fig. I summarize the results of these studies. They show that powdered iron is very much less available than ferrous sulphate. The original findings for each subject show that the ratio between powdered iron and ferrous sulphate increases as absorption is raised, for example in iron-deficient subjects. The results for reduced iron BP suggest that its availability is much closer to that of powdered iron, though it is probably less available to normal and iron-deficient

Table 4. Mean percentage absorptions of iron preparations by human subjects with and without achlorhydria, some of whom were given an egg as part of the standard breakfast

\begin{tabular}{|c|c|c|c|c|}
\hline \multirow[b]{2}{*}{ Subgroup } & \multirow{2}{*}{$\begin{array}{l}\text { Reduced } \\
\text { iron }\end{array}$} & \multicolumn{2}{|c|}{ Ferric ammonium citrate } & \multirow{2}{*}{$\begin{array}{l}\text { Powdered } \\
\text { iron }\end{array}$} \\
\hline & & Green & Brown & \\
\hline \multicolumn{5}{|l|}{$\begin{array}{l}\text { 'Normal' and 'iron- } \\
\text { deficient' subjects: }\end{array}$} \\
\hline Given an egg & $\begin{array}{l}0.85(0.95) \\
\text { I3 subjects }\end{array}$ & $\begin{array}{l}\text { I.06 (0.88) } \\
\text { I3 subjects }\end{array}$ & * & $\begin{array}{l}0.28 \quad(3.45) \\
\mathrm{r}_{4} \text { subjects }\end{array}$ \\
\hline Not given an egg & $\begin{array}{c}5 \cdot 10(\mathrm{II} \cdot 68) \\
9 \text { subjects }\end{array}$ & - & $\begin{array}{l}12 \cdot 24(14 \cdot 00) \\
9 \text { subjects }\end{array}$ & $\begin{array}{c}\text { I. I3 }(23 \cdot 47) \\
6 \text { subjects }\end{array}$ \\
\hline \\
\hline Given an egg & - & - & - & $\begin{array}{c}0.14 \quad(0.70) \\
4 \text { subjects }\end{array}$ \\
\hline Not given an egg & $\begin{array}{l}\text { I.12 }(3 \cdot 50) \\
6 \text { subjects }\end{array}$ & - & - & - \\
\hline
\end{tabular}

Figures in parentheses are mean absorptions of ferrous sulphate in the same groups of subjects.

*Three results only from pilot experiment, $0.5 \%, 0.9 \%$ and $8.0 \%$. 


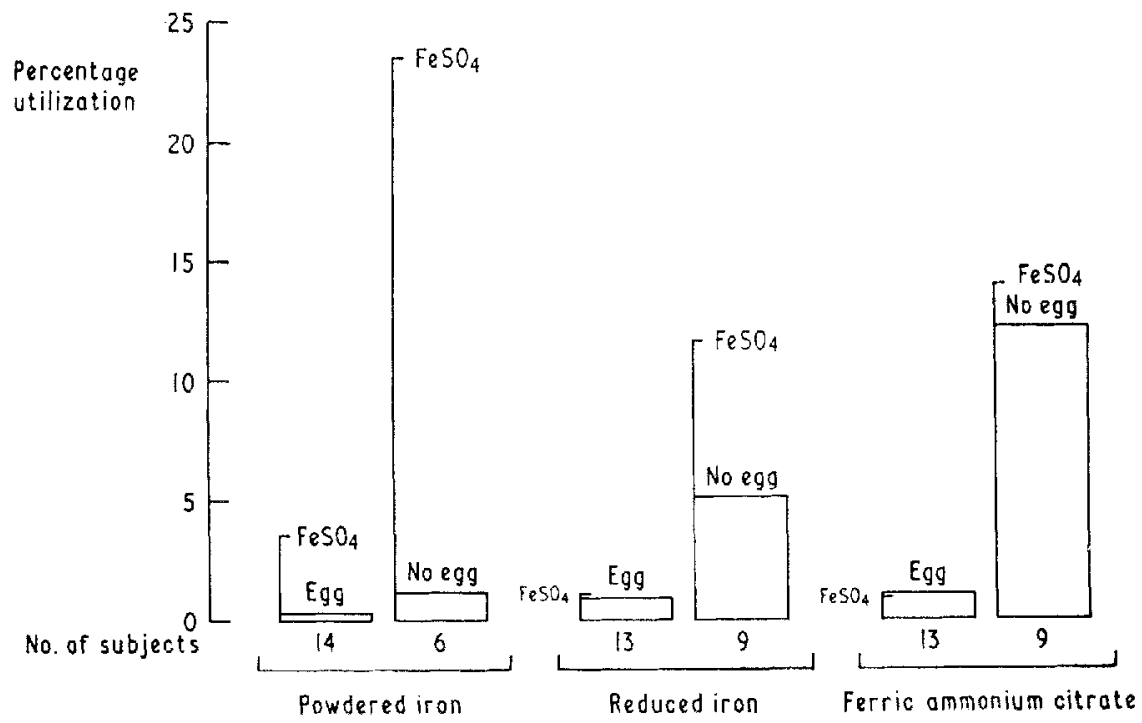

Fig. 1. Percentage utilization by human subjects of iron in bread, determined by the double radiaisotope method. All subjects received bread into which ferrous iron was baked and, in addition, bread containing either powdered iron, reduced iron or ferric ammonium sulphate; some received an egg.

subjects, and almost certainly much less available to subjects with gastric achlorhydria. On the other hand, the differences in availability of ferric ammonium citrate and ferrous sulphate are small and probably unimportant.

Unfortunately we have no information relating to sodium iron pyrophosphate. Although this is a more expensive preparation than reduced iron it is said to be particularly suitable for use in the food industry as it is light coloured (Wilder \& Williams, 1944). However, the availability to anaemic rats of sodium pyrophosphate or sodium ferric pyrophosphate appears to be low compared to that of a wide variety of iron preparations (Freeman \& Burrill, r945; Street, r 943; Blumberg \& Arnold, I947). On the other hand, Steinkamp, Dubach \& Moore (I955), on the basis of the absorption of a single radioactive dose, state that sodium iron pyrophosphate is as readily available to human subjects from bread as a variety of other iron preparations, including ferrous sulphate and reduced iron, though only eight subjects were given sodium iron pyrophosphate in their studies. However, it seems that sodium iron pyrophosphate or sodium ferric pyrophosphate is not a single salt and the substance so called which was prepared and tested by Steinkamp et al. (1955), a green crystalline substance, soluble in water, does not appear to be the same as that which is used for the enrichment of flour in the United States, which is a white powder, insoluble in water. Because of the difficulty in defining a single iron salt with this name we decided not to include in our studies any of the iron preparations given this name.

It is also clear from Table 4 and Fig. $I$. that the presence of an egg in our standard breakfast had a very marked inhibitory effect on the availability of iron from bread. While the studies of Bergeim \& Kirch ( (1949), Chodos, Ross, Apt, Pollycove \& Halkett (1957) and others led us to expect some reduction in the absorption of iron in our 
experiments, we decided to include an egg in our standard breakfast to make it a realistic meal. The consequent effect on iron absorption appears to have been far greater than we could possibly have expected on the basis of the published findings of these authors, and the inhibitory effects of egg would therefore appear to be much greater on an iron salt incorporated into a foodstuff than on an iron salt given separately with a meal, possibly because of the greater dispersion throughout the meal of iron incorporated into bread. The importance of egg in this context seems to be considerable both because of the apparent magnitude of its effect, and because of the very frequent use of egg and cereals together in certain breads, cakes, and, possibly of even greater importance, infant foods. It is of interest in this context that certain other commonly consumed foodstuffs such as milk (Abernathy, Miller, Wentworth \& Spiers, 1965) and possibly foods with a high protein content (Sorensen 1964) have also an inhibitory effect on iron absorption.

Ideally, studies of the effect of dietary measures such as the addition of iron to flour should be assessed in long-term trials based on community feeding. The results of animal studies or human 'laboratory-type' experiments with 'standard' meals may be misleading, and are always impossible to interpret with confidence in terms of an effect on the community. Unfortunately, however, a clinical trial which, with a reasonable degree of certainty, would be likely to detect as statistically significant the effect on haemoglobin level of the daily addition of a few $\mathrm{mg}$ of iron to the diet would be a formidable undertaking. Any such trial is likely to have a high 'error of the second kind' (Armitage I960); that is, the probability of failing to detect a beneficial effect, if one does occur, as statistically significant, is high. A negative result in such a study, if one is conducted, should therefore not necessarily be accepted as evidence that the addition of iron to flour is without benefit.

\section{Conclusion}

We feel that iron deficiency anaemia has largely ceased to be an important subject for clinical research. The initiative has largely passed to the epidemiologist as only in community studies can an unbiased evaluation of haemoglobin level as an index of health be made, and only in community studies can the long-term effects of prophylactic measures adopted at a national level be assessed. We feel too that the epidemiologist has a similar part to play in relation to other haematological and biochemical variates. Biochemical tests can all too easily be developed and accepted into clinical practice with little more than the definition of a 'normal range', which seems to present little difficulty in a teaching medical centre. It is much more difficult to obtain an unbiased estimate of the distribution of a variate in the population, to 'validate' this distribution in terms of an independent index of morbidity or mortality, and subsequently to explore preventive measures applicable to the community. 'These latter are the most profitable fields of research for the epidemiologist, and his work, perhaps more than that of any other medical research worker, is of relevance to national policy and the public health.

Dr W. T. C. Berry, Professor A. L. Cochrane and Professor J. Pemberton deserve much of the credit for the original work described in this paper. 


\section{REFERENCES}

Abernathy, R. P., Miller, J., Wentworth, J. \& Spiers, M. (1965). J. Nutr. 85, 265.

Antila, V. (1 962). Acta med. scand. suppl. 393, p. I.

Armitage, P. (1960). Sequential Medical Trials. Oxford: Blackwell.

Bergeim, O. \& Kirch, E. R. (1949). F. biol. Chem. r77, 59 I.

Beutler, E., Larsh, S. E. \& Gurney, C. W. (1960). Ann. intern. Med. 52, 378.

Birnbaum, M. (1963). Am. Heart F. 65, 136.

Blumberg, H. \& Arnold, A. (r947). Cereal Chem. 24, 303.

Burch, G. E. \& De Pasquale, N. P. (1962). Am. F. Med. 32, 161.

Chodos, R. B., Ross, J. F., Apt, L. Pollycove, M. \& Halkett, J. A. E. (I957). J. clin. Invest. 36, 314.

D'Arcy, P. F. \& Howard, E. M. (1962). Pharm. F. r89, 223.

Dawber, T. R. \& Kannel, W. B. ( (96I). Mod. Concepts cardiovasc. Dis. 30, 671.

De Leeuw, N. K. M., Lowenstein, L. \& Yang-Shu, H. (1966). Medicine, Baltimore, 45, no. 4, p. 29 I.

Eakins, J. D. \& Brown, D. A. (1965). United Kingdom Atomic Energy Authority : Research Group Report : A.E.R.E.-R. 4945 .

Eisenberg, S. (1966). Circulation 33, suppl. 2, p. 10.

Elwood, P. C. (I963). Br. med. F. i, 224.

Elwood, P. C. $\left(\right.$ I964) $_{4}$. Br. F. prez. soc. Med. I8, 8ז.

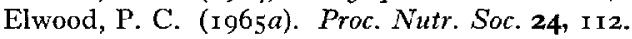

Elwood, P. C. $(1965 b)$, Nutrition, Lond, 19, 158 .

Elwood, P. C. (1966). Nutritio Dieta 8, 2 10.

Elwood, P. C., Waters, W. E., Greene, W. J. \& Wood, M. M. (1967). Br. med. F. ii, 7r4.

Elwood, P. C., Withey, J. L. \& Kilpatrick, G. S. (1964). Br. F. prev. soc, Med. r8, r25.

Elwood, P. C. \& Wood, M. M. (1966). Br. F. prev. soc. Med. 20, 172.

Freeman, S. \& Burrill, M. W. (1945). F. Nutr. 30, 293.

Garby, L., Irnell, L. \& Werner, I. (1966). Acta Sac. Med. upsal. 72, 91.

Garry, R. C., Sloan, A. W., Weir, J. B. De V. \& Wishart, M. (1954). Br. F. Nutr, 8, 253.

Great Britain: Parliament (1953). The Flour Order, 1953. Stat. Instrum. 1282.

Great Britain: Parliament. (1963). Bread and Flour Regulations, 1963. Stat. Instrum. 1435.

Harrill, I. K., Hoene, A. E. \& Johnston, F. A. (1957). \%. Am. diet. Ass. 33, гого.

Harris, J. W. (1963). The Red Cell. Harvard: University Press.

Kilpatrick, G. S. (1961). Br. med. F. ii, 1736 .

Kilpatrick, G. S. \& Hardisty, R. M. (I96r). Br. med. 7. i, 778.

Mackay, I. M. M., Dobbs, R. N. \& Bingham, K. (1945). Archs Dis. Childh. 20, 56.

Ministry of Agriculture, Fisheries and Food: National Food Survey Committee (1963). Domestic Food Consumption and Expenditure, i 96 . London: H.M. Stationery Office.

Murphy, E. A. \& Abbey, H. (1967). F. chron. Dis. 20, 79.

Natvig; H., Bjerkedal, T. \& Jonassen, O. (1963). Acta med. scand. 174, 35 r.

Paintin, D. B., Thompson, A. M. \& Hytten, F. E. (1966). F. Obstet. Gynaec. Br. Emp. 58, I73.

Parsons, P. L., Withey, J. L. \& Kilpatrick, G. S. (1965). Practitioner 195, 656.

Scott, E. M. \& Heller, C. A. (r964). Am. F. clin. Nutr. т5, 282.

Sorensen, E. W. (1964). Acta med. scand. 175, 763 .

Steinkamp, R., Dubach, R. \& Moore, C. V. (1955). Archs intern. Med. 95, I8I.

Strcet, H. R. (1 943). $\mathscr{F}$. Nutr. 26, 187.

W.H.O. (1959). Tech. Rep. Ser. Wld Hlth Org. no. 182.

Widdowson, E. M. \& McCance, R. A. (I 954). Spec. Rep. Ser. med. Res, Coun. no. 287.

Wilder, R. M. \& Williams, R. R. (1944). Bull. natn. Res. Coun., Wash. no. I 10, 38.

Wood, M. M. \& Elwood, P. C. (r966). Br. J. prev. soc. Med. 20, I17. 